\title{
Endothelial Cell Activation, Reduced Endothelial Cell Reparative Capacity, and Impaired Endothelial-dependent Vasodilation After Anger Provocation
}

\author{
Daichi Shimbo, MD ${ }^{1,{ }^{*}}$, Leah B. Rosenberg, MD², William Chaplin, PhD $^{3}$, Shuqing Zhao, \\ MS $^{1}$, Emma R. Goldensohn, BA ${ }^{1}$, Matthew Cholankeril, MD ${ }^{1}$, Jie Fu, MS ${ }^{1}$, Sang Been Hong, \\ BA $^{1}$, Sanja Jelic, $\mathbf{M D}^{1}$, and Matthew M. Burg, PhD $^{1}$ \\ ${ }^{1}$ Department of Medicine, Columbia University Medical Center, New York, NY \\ ${ }^{2}$ Department of Medicine, Duke University Medical Center, Durham, NC \\ ${ }^{3}$ Department of Psychology, St. John's University, New York, NY
}

\section{Keywords}

Anger; endothelial function; cell-derived microparticles; progenitor cells

\begin{abstract}
The experience of anger increases the acute and long-term risks of incident cardiovascular disease (CVD) events [1,2]. The mechanism(s) whereby anger is associated with increased CVD risk remains to be fully characterized. One promising candidate mechanism is endothelial dysfunction. Endothelial dysfunction, as evidenced by impaired endothelialdependent vasodilation, is an early pathogenic process underlying atherosclerosis development and CVD onset. More recent investigations have elucidated the cellular pathways underlying endothelial dysfunction. Endothelial cell (EC) injury, assessed by measuring circulating levels of EC-derived microparticles (EMPs), are phospholipid rich, submicron particles derived and released from the membranes of activated or apoptotic ECs [3]. In addition, the discovery of circulating, bone marrow-derived endothelial progenitor cells (EPCs) capable of EC repair and regeneration [4] suggests that endothelial function represents a balance between ongoing injury and repair.
\end{abstract}

We previously reported that anger provocation acutely impairs arterial vasomotion in apparently healthy individuals [5]. We conducted a study to examine the acute effects of anger provocation not only on arterial vasodilation but also on levels of EMPs and bone marrow-derived EPCs. To our knowledge, this is the first report concerning the adverse effects of anger provocation on cellular pathways underlying EC health.

(C) 2012 Elsevier Ireland Ltd. All rights reserved.

Corresponding Author: Daichi Shimbo, MD, Center for Behavioral Cardiovascular Health, 622 West 168th Street, PH 9-310, Columbia University Medical Center, New York, New York, 10032. ds2231@ columbia.edu. Phone: 212-342-4490; Fax: 646-304-7003.

*All authors take responsibility for all aspects of the reliability and freedom from bias of the data presented and their discussed interpretation.

Conflicts of Interest: There are no conflicts of interest to report.

Publisher's Disclaimer: This is a PDF file of an unedited manuscript that has been accepted for publication. As a service to our customers we are providing this early version of the manuscript. The manuscript will undergo copyediting, typesetting, and review of the resulting proof before it is published in its final citable form. Please note that during the production process errors may be discovered which could affect the content, and all legal disclaimers that apply to the journal pertain. 
Thirty apparently healthy participants $(63.3 \%$ female, $37.3 \pm 12.9$ years old $)$ completed a morning laboratory session that included sequential rest, a 12-minute standardized anger recall task [6], and a recovery period. In a separate experiment to examine the effect of diurnal variations and experimental procedures on endothelial function, six participants matched for age and sex (66.7\% female, $35.5 \pm 13.9$ years old) completed a comparable morning laboratory session in which the anger recall task was replaced with a 12-minute emotionally neutral task. In the latter condition, the participants were asked to count aloud by ones, starting with one and ending with 50 , over and over at their own pace, until the task period elapsed. All participants reported to the laboratory at $8 \mathrm{AM}$ in a fasting state and having refrained from exercise for 12 hours. The study protocol, which was approved by the Institutional Review Board of Columbia University Medical Center, conforms to the ethical guidelines of the 1975 Declaration of Helsinki. Written informed consent was obtained from all participants. The authors of this manuscript have certified that they comply with the Principles of Ethical Publishing in the International Journal of Cardiology (Int J Cardiol. 2011;153:239-40).

Blood was drawn from an indwelling catheter at baseline, and 30 and 90 minutes post-anger or neutral task, and collected into tubes containing citrate for the assessment of EMPs and EDTA for the measurement of EPCs. Each blood draw was followed by endotheliumdependent vasodilation testing. CD62E+ and CD31+ endothelial microparticles (EMPs), phenotypic for EC activation and apoptosis respectively [3], and KDR+, CD34+, and CD133+ bone marrow-derived endothelial progenitor cells (early EPCs) [7] were quantified by flow cytometry. Endothelial-dependent vasodilation was determined by the reactive hyperemia index (RHI) using peripheral arterial tonometry [8]. Systolic and diastolic blood pressure (SBP/DBP) and heart rate (HR) were measured using a TNO Finometer Continuous Blood Pressure Monitor. Additional information about the study methods is provided in the online supplement. Data are given as mean \pm standard deviation (SD). Repeated measures multivariate analysis of variance was used to test the effect of the task on RHI, EMPs, EPCs, and hemodynamic parameters over time.

From baseline across the post-anger recall task recovery period (Table 1), RHI significantly decreased, levels of EMPs expressing CD62E significantly increased, and levels of early EPCs significantly decreased. Further, SBP, DBP, and HR significantly increased across the 3 time points following anger recall. There were no significant correlations ( $\mathrm{ps}>0.05$ ) of changes in hemodynamic parameters (SBP, DBP, and HR) with changes in RHI, EMPs expressing CD62E, and EPCs, from baseline to 30 minutes, from 30 to 90 minutes, and from baseline to 90 minutes.

In the neutral condition, RHI significantly increased from baseline across the post-task recovery period (baseline $1.74 \pm 0.43,30$ minutes $2.38 \pm 0.57$, and 90 minutes $2.50 \pm 0.60$; $\mathrm{p}=0.014)$. There were no significant differences across the 3 time points in the level of EMPs expressing CD62E (baseline 339 $191 \mathrm{EMP} / \mathrm{uL}, 30$ minutes $341 \pm 227 \mathrm{EMP} / \mathrm{uL}$, and 90 minutes $360 \pm 176 \mathrm{EMP} / \mathrm{uL} ; \mathrm{p}=0.455$ ) and also early EPCS (baseline $0.026 \pm 0.015 \%, 30$ minutes $0.022 \pm 0.013 \%$, and 90 minutes $0.024 \pm 0.011 \%$; $\mathrm{p}=0.465$ ). Within each condition (anger and neutral), the results for RHI, EMPs expressing CD62E, and early EPCs across time were similar after adjusting for baseline values (results not shown).

We found that a brief anger provocation was associated with an acute impairment in endothelium-dependent vasodilation, EC activation, and reduction in EC reparative capacity. These data demonstrate for the first time that anger provocation adversely affects multiple pathways of EC health, and suggests a mechanistic pathway by which anger is associated with increased incident CVD risk. The unifying biological pathway by which anger adversely affects EC health is unknown. One possible pathway is anger-related 
hemodynamic effects. However, in our study, hemodynamic changes associated with anger provocation did not contribute to changes in endothelium-dependent vasodilation, EMPs, and EPCs. Other possible stress-related mechanisms include dysregulation in the hypothalamic-pituitary-adrenal axis, autonomic nervous system imbalance, endothelin-1 release, and reduced nitric oxide bioavailability via oxidative stress. Future investigations should examine the specific mechanisms by which provoked anger is associated with endothelial dysfunction.

Endothelium-dependent vasodilation increased across the three time points in the neutral condition whereas circulating EMPs and EPCs remained unchanged. These findings are consistent with previous studies demonstrating diurnal increases in endothelium-dependent vasodilation [9] and no changes in circulating progenitor cells [10] between $6 \mathrm{AM}$ and 12 PM. To our knowledge, no previous studies have examined the diurnal variation in EMPs. Our findings suggest that changes in EMPs do not occur during a morning session.

The results of this study help to characterize how anger might exacerbate the onset of atherosclerosis and CVD events at the cellular level. Future research is needed to replicate these novel findings. In addition to investigating the biological mechanisms underlying the link between provoked anger and endothelial dysfunction, studies should also delve into whether the induction of other negative emotions has similar adverse effects on EC health.

\section{Supplementary Material}

Refer to Web version on PubMed Central for supplementary material.

\section{Acknowledgments}

This work was supported by the National Institutes of Health (HL-076857 from the National Heart, Lung, and Blood Institute), Bethesda, Maryland, and the Stanley J. Sarnoff Cardiovascular Research Foundation, Great Falls, Virginia; and in part by Columbia University's CTSA grant No. UL1 RR024156 from NCATS-NCRR/National Institutes of Health. The content is solely the responsibility of the authors and does not necessarily represent the official views of either the National Institutes of Health or Stanley J. Sarnoff Cardiovascular Research Foundation. The authors of this manuscript have certified that they comply with the Principles of Ethical Publishing in the International Journal of Cardiology (Coats AJS and Shewan LG. Statement on Authorship and Publishing Ethics in the International Journal of Cardiology. Int J Cardiol. 2011;153:239-40).

\section{References}

1. Mittleman MA, Maclure M, Sherwood JB, Mulry RP, Tofler GH, Jacobs SC, et al. Triggering of acute myocardial infarction onset by episodes of anger. Determinants of Myocardial Infarction Onset Study Investigators. Circulation. 1995; 92:1720-5. [PubMed: 7671353]

2. Chang PP, Ford DE, Meoni LA, Wang NY, Klag MJ. Anger in young men and subsequent premature cardiovascular disease: the precursors study. Arch Intern Med. 2002; 162:901-6. [PubMed: 11966341]

3. Jimenez JJ, Jy W, Mauro LM, Soderland C, Horstman LL, Ahn YS. Endothelial cells release phenotypically and quantitatively distinct microparticles in activation and apoptosis. Thromb Res. 2003; 109:175-80. [PubMed: 12757771]

4. Urbich C, Dimmeler S. Endothelial progenitor cells: characterization and role in vascular biology. Circ Res. 2004; 95:343-53. [PubMed: 15321944]

5. Shimbo D, Chaplin W, Akinola O, Harris A, Abraham D, Homma S, et al. Effect of anger provocation on endothelium-dependent and -independent vasodilation. The American journal of cardiology. 2007; 99:860-3. [PubMed: 17350383]

6. Burg MM, Graeber B, Vashist A, Collins D, Earley C, Liu J, et al. Noninvasive detection of risk for emotion-provoked myocardial ischemia. Psychosom Med. 2009; 71:14-20. [PubMed: 18941131] 
7. Jelic S, Padeletti M, Kawut SM, Higgins C, Canfield SM, Onat D, et al. Inflammation, oxidative stress, and repair capacity of the vascular endothelium in obstructive sleep apnea. Circulation. 2008; 117:2270-8. [PubMed: 18413499]

8. Rubinshtein R, Kuvin JT, Soffler M, Lennon RJ, Lavi S, Nelson RE, et al. Assessment of endothelial function by non-invasive peripheral arterial tonometry predicts late cardiovascular adverse events. European heart journal. 2010; 31:1142-8. [PubMed: 20181680]

9. Otto ME, Svatikova A, Barretto RB, Santos S, Hoffmann M, Khandheria B, et al. Early morning attenuation of endothelial function in healthy humans. Circulation. 2004; 109:2507-10. [PubMed: 15136499]

10. Watson T, Shantsila E, Karthikeyan VJ, Jessani S, Goon PK, Lip GY. The effects of exercise stress testing, diurnal variation and temporal decline on circulating progenitor cells. Thromb Haemost. 2010; 103:419-25. [PubMed: 20126832] 


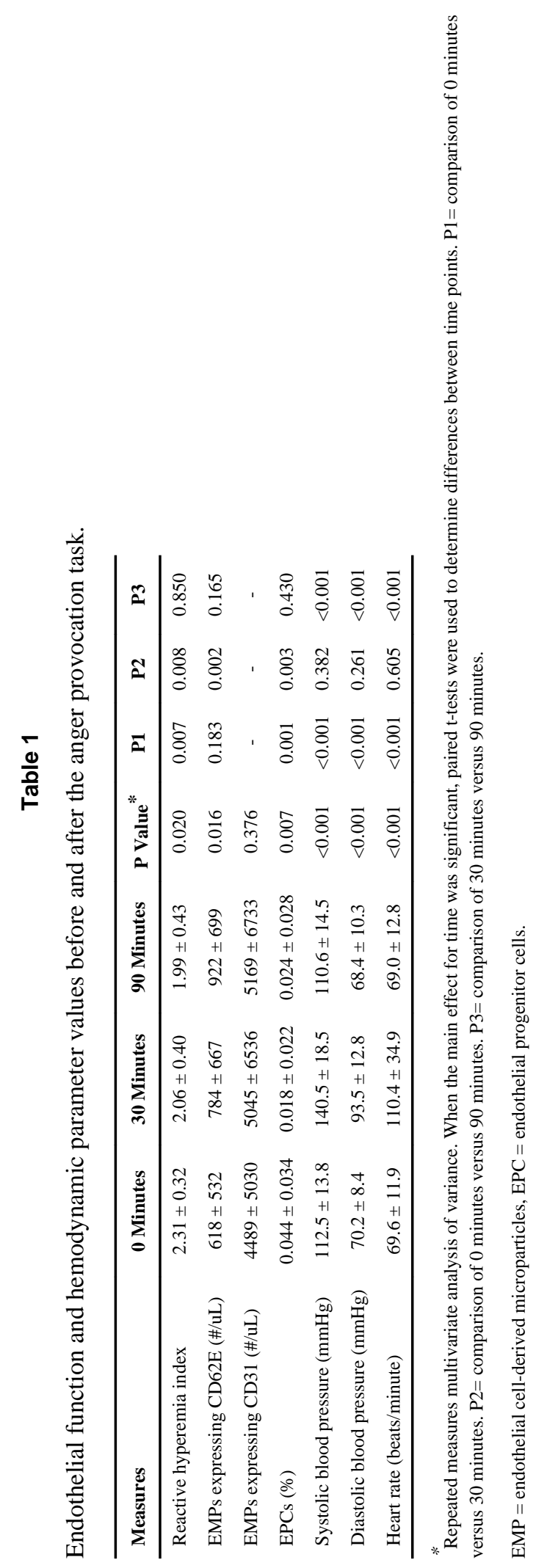

Int J Cardiol. Author manuscript; available in PMC 2014 August 10. 